\title{
Parque Municipal Salto da Pedreira em Rio Azul, PR: uma proposta de reestruturação do circuito de trilhas
}

\section{Salto da Pedreira Municipal Park in Rio Azul, PR: a proposal of restructuring the trails circuit}

Parque Municipal Salto da Pedreira en el Rio Azul, PR: una propuesta de reestructuracción del circuito de sendero

\section{Janaina Sakowicz ${ }^{1}$ \\ Ronaldo Ferreira Maganhotto ${ }^{2}$}

${ }^{1}$ Mestranda em Desenvolvimento Comunitário pela Universidade Estadual do Centro-Oeste (Unicentro). Pós-Graduada em Educação Ambiental (FACEL). Bacharel em Turismo (Unicentro). Técnica em Meio Ambiente (IFPR). E-mail: janadsak@hotmail.com

${ }^{2}$ Doutor em Geografia pela Universidade Federal do Paraná (UFPR). Professor na Universidade Estadual do Centro-Oeste (Unicentro). Mestrado em Geografia

(UFPR). Pós-Graduado em Análise Ambiental (UFPR). Graduação em Turismo pela Universidade Estadual de Ponta Grossa (UEPG). Graduação em Geografia pela Uninter. E-mail: ronaldomaganhotto@gmail.com 
Resumo : Este trabalho apresenta uma proposta de melhorias na infraestrutura das trilhas do Parque Municipal Salto da Pedreira, no município de Rio Azul, estado do Paraná. O local é público, o uso do mesmo e de seus recursos incluindo as trilhas, se dá principalmente nos finais de semana. A pesquisa foi feita a partir de um estudo de caso com observação do lugar, e das duas trilhas existentes, a fim de se saber como se dá o uso destas bem como seu estado de conservação. A partir dessas observações, são apresentadas nos resultados propostas de melhorias para os pontos mais críticos dos traçados.

Palavras-chave: trilhas; reestruturação; planejamento de trilhas; parque municipal.

Abstract: This work presentes a proponesal for improvements on infrastructure of Parque Municipal Salto da Pedreira trails, in Rio Azul town, Paraná state. The place is public, the use of it and its resources including the trails, is mainly on the weekends.The search was based on a case study and with observation of the place, and the two existing trails, in order to know how is the use of these as well as your conservation. From these observations, improvements are presented in the results for the most critical points of the track.

Keywords: trails; restructuring; planning of trails; municipal park.

Resumen: Este trabajo presenta una propuesta de mejoras en la insfraestructura de los senderos del Parque Municipal Salto da Pedreira, en el município de Rio Azul, estado de PR. El lugar es público incluyendo los senderos, se da principalmente los fines de semana. La investigación fue hecha a partir de un estudio de caso con observación del lugar, y de las dos senderos existentes, com el fin de saber cómo es el uso de éstas así como su estado de conservación. A partir de estas observaciones, se presentan em los resultados propuestos de mejoras para los puntos más críticos de los trazados.

Palabras clave: senderos, reestructuracción; planeamento de senderos; parque municipal. 


\section{INTRODUÇÃO}

As trilhas surgiram da necessidade de deslocamento das pessoas, configurando-se como meio mais antigo de o homem se deslocar. Possibilita a aproximação entre o ser humano e a natureza, proporcionando, além do acesso a áreas de grande riqueza natural, a preservação do ambiente, fomentando a sensibilização dos usuários quanto à proteção do patrimônio natural. No entanto os benefícios trazidos com a utilização adequada desses traçados estão relacionados ao seu planejamento, implantação e manutenção adequados, pois uma trilha não planejada e não monitorada pode resultar em danos ambientais em parques e demais locais em que estão localizadas.

O Parque Municipal Salto da Pedreira, objeto de estudo desta pesquisa, é situado na BR 153 a 8 km da cidade de Rio Azul, estado do Paraná, e tem visitação frequente da população local e regional. Seu uso está voltado para o lazer e recreação o ano todo, mais intensamente entre os meses de outubro a abril. A visitação no Parque, o que inclui as trilhas, é feita nos finais de semana e ocorre de forma desordenada, devido à não existência de um controle da entrada e orientação dos visitantes. Nesse contexto, foi identificado como problema de pesquisa a seguinte questão:

O circuito de trilhas do Parque Salto da Pedreira necessita de ações de reestruturação?

Assim, o presente trabalho tem como objetivo geral propor ações de melhorias para o circuito de trilhas do Parque Salto da Pedreira. O cumprimento deste está relacionado à concretização dos objetivos específicos, os quais priorizam: identificar os impactos presentes nas trilhas; localizar pontos dos traçados que necessitam de infraestrutura e sugerir locais para implantação de informações relacionadas às trilhas.

Dos procedimentos metodológicos, primeiramente foi feito o enfoque teórico, o qual permitiu conhecer sobre a temática trabalhada na pesquisa tratando sobre: turismo em áreas naturais; trilhas; planejamento e implantação de trilhas e infraestrutura nas trilhas. Em um segundo momento, foi feita uma pesquisa exploratória e escolhido o método de estudo de caso, para que se pudesse obter um conhecimento aprofundado sobre o local e seus atrativos. Também foi realizada observação simples e registros foto- 
gráficos a fim de saber como é feito o uso da trilha e se há necessidade de melhorias para aperfeiçoamento do traçado.

\section{TURISMO EM ÁREAS NATURAIS}

Para Oliveira (2002), o turismo pode ser qualquer produto intangível que tem a capacidade de satisfazer as necessidades dos seres humanos em termos de lazer, diversão, ocupação do tempo livre por meio de atividades no ambiente natural, conhecimento sobre o local visitado bem como os costumes e tradições das comunidades. O autor denomina o turismo como sendo

[...] o conjunto de resultados de caráter econômico, financeiro, político, social e cultural produzidos numa localidade, decorrentes do relacionamento entre os visitantes com os locais visitados durante a presença temporária de pessoas que se deslocam de seu local habitual de residência para outros, de forma espontânea e sem fins lucrativos. (OLIVEIRA, 2002, p. 36).

Ainda afirma que a atividade deve ser praticada voluntariamente não sendo convertida a fins lucrativos. O relacionamento entre os visitantes e a comunidade receptora deve ser estável para que ambas as partes possam aproveitar o turismo da melhor forma, e que esta não interfira no modo de vida dos residentes locais.

O ser humano sempre se sentiu bem em estar próximo da natureza, porém tinha-se o pensamento de que os recursos naturais eram inesgotáveis, e, com a demanda por áreas naturais, os danos gerados a partir do uso demasiado se potencializaram; depois disso, a partir da década de 1970, o princípio de preservação ambiental passou a ser mais discutido, e a relação entre o homem e o ambiente natural a serem refletidos (KINKER, 2002).

Os recursos naturais são atrações para os turistas, contudo, muitas vezes, o desenvolvimento do turismo e o uso de uma área da natureza geram impactos ambientais. Portanto é necessário desenvolver e gerenciar os recursos adequadamente para que não ocorram danos graves ao ambiente, seu uso deve ampliar os benefícios vindos com o desenvolvimento da atividade, já que o turismo pode ser um caminho para o desenvolvimento sustentável (LICKORISH; JENKINS, 2000). 
Parque Municipal Salto da Pedreira em Rio Azul, PR: uma proposta de reestruturação do circuito de trilhas

De acordo com D’amore (1993 apud KINKER, 2002, p. 18), a demanda pelo turismo em áreas naturais se relaciona aos seguintes fatores: "a procura por maior qualidade de vida, quando o homem sente necessidade de achar um espaço fora do urbano e do caos, que transmita calma e alivie o estresse, o surgimento e o fortalecimento de uma ética ambiental".

Frente a isto, percebe-se que o aumento da procura por áreas naturais, em busca por maior contato com a natureza, se deu diante da procura por algo fora da rotina comum, de um ambiente em que se fosse possível a aproximação do homem com o natural. Em relação ao turismo e ambiente natural, Ruschmann (1997) frisa que entre turismo e meio ambiente existe uma relação incontestável, já que o meio é a matéria prima da atividade. O contato com a natureza é uma das maiores motivações das viagens, e as consequências do turismo de massa devem ser analisadas, e seus efeitos negativos evitados, buscando proteger o patrimônio, evitando ações que tragam danos ao ambiente, apesar de o turismo não ser o único culpado pelas agressões à natureza, pois existem outros fatores que contribuem na geração de impactos ambientais. É imprescindível a harmonia entre a atividade turística e a natureza, pois, se não houver equilíbrio com o meio ambiente, o turismo comprometerá sua própria existência.

Nessa mesma afirmativa, Dias (2003) diz que a relação do turismo com a natureza é permanente, pois ela é sua atração principal. No entanto é necessário o cuidado com o ambiente natural, sem o qual o turismo não existe. Além do planejamento e monitoramento, ações de educação ambiental devem ser praticadas dentro e fora do meio natural, pois a consciência sobre conservação do ambiente deve ser contínua.

Sabendo que o impacto gerado em ambientes naturais é inevitável, o que se pode fazer para minimizá-los é manter a atividade dentro de limites que sejam aceitáveis e objetivando maximizar os impactos positivos gerados sobre o meio. Um planejamento adequado da atividade turística traz benefícios ao meio, promovendo a conservação da natureza. Uma vez que o turismo tem como protagonista de sua existência os recursos naturais, deve-se priorizar que este patrimônio seja desenvolvido de forma sustentável (DIAS, 2003).

A relação das trilhas com a atividade turística se dá como um elemento que parte da aproximação do homem com a natureza e também é 
uma opção para diversificar a oferta turística de um lugar. O uso das trilhas proporciona conhecimento sobre o ambiente a partir da observação da natureza durante a caminhada, formando uma consciência de resguardo perante o ambiente natural, para que assim os usuários da trilha tenham mais atenção sobre o local visitado (ANDRADE; OLIVEIRA; MAGANHOTTO, 2011).

Com o crescimento da demanda por áreas naturais, a busca por triIhas também aumentou, junto com a prática do ecoturismo que envolve a caminhada utilizando de trilhas para deslocamento. Estas, por sua vez, oferecem uma forma tranquila de se obter o contato com a natureza, bem como uma prática de lazer. A procura por áreas naturais gera a valorização desses aspectos e maior percepção sobre o cuidado que o ambiente necessita (ANDRADE, 2003).

É importante ressaltar a criação dos parques, os quais também utilizam do ambiente natural como principal atrativo e onde também podem ser realizadas trilhas. Parque pode ser compreendido como um espaço para atividades de lazer, recreação e prática de esportes ao ar livre, um meio de se utilizar do espaço natural buscando uma forma de distração ou ócio (FENNEL, 2002 ). A realização de caminhadas por trilhas é uma atividade que se utiliza diretamente do meio; se esta for bem planejada e estruturada, pode fortalecer as ações de conservação e educação ambiental, bem como ser um instrumento de conhecimento de locais que só podem ser acessados por meio de trilhas.

\section{TRILHAS}

As trilhas são uma alternativa para a valorização ambiental nos segmentos turísticos que utilizam das áreas naturais, como o ecoturismo e o turismo de aventura. É um instrumento capaz de destacar as características do ambiente, repercutindo diretamente no comportamento dos turistas. As trilhas possibilitam a prática de diversas atividades como, trekking (seguir por uma trilha ou percurso a pé) e também o ciclismo que possibilita o acesso aos diversos atrativos.

Bruhns (2006 apud LAVOURA; SCHWARTZ; MACHADO, 2008) aponta que o caminhar por uma trilha em ambiente natural pode ser um exercício 
aos sentidos, e promove contato com o meio, podendo se configurar como forma de interpretação deste. Trilhas condizem a espaços de aventura, pois envolvem caminhadas em variados níveis de dificuldade, além da observação, que também é característica do turismo de aventura, promovendo a interação do usuário com o ambiente. Trilha é uma palavra vinda do latim tribulum, tendo por significado direção, caminho e rumo. Tem origem, de acordo com Andrade (2003), na decorrência da migração de animais que se deslocavam em busca de alimento e água, ou em fuga das mudanças climáticas bruscas.

De acordo com o Instituto Brasileiro de Turismo Embratur (EMBRATUR, 1994, p. 9), "trilhas são corredores de circulação bem definidos dentro da área protegida e através dos quais os visitantes são conduzidos a locais de grande beleza natural para observação da natureza", sendo que estes se apresentam como forma de estabelecer contato com o ambiente natural. Portanto o uso das trilhas sofreu alteração de valores com o passar dos anos, deixando de ser apenas meio de deslocamento para uma forma de se ter contato com o meio natural, surgindo um novo sentido para a utilização desses trajetos.

No Brasil os primeiros relatos referentes a trilhas são da época pré-cabralina, sendo a introdução na Serra do Mar; após estas, outras foram sendo abertas. Esses corredores foram utilizados como estradas de acesso no desbravamento das terras brasileiras, para pesquisas científicas e estudo dos recursos naturais (ANDRADE, 2003). As trilhas são classificadas quanto à sua função. Podem ser utilizadas pelo poder público e por visitantes, ainda podem ser de curta distância, as quais apresentam caráter educativo como as trilhas interpretativas, e de longo percurso, chamadas trilhas selvagens que envolvem deslocamentos de longas distâncias (ANDRADE, 2003).

As trilhas também podem ser classificadas de acordo com sua dificuldade, esta pode ser calculada pela altitude média do local, extensão da trilha, condições climáticas, obstáculos presentes no trajeto, diferentes ângulos de aclives e declives, condições físicas exigidas dos usuários, dentre outros fatores que contribuem para avaliar o grau de dificuldade de uma trilha, como a duração da caminhada, atrativos encontrados no percurso, bem como a falta de manutenção do trajeto (PAPINI; COSTA; COSTA, 2006). 
Trilhas não são apenas uma forma para difundir conhecimentos e podem ser caracterizadas como interpretativas, que tem o objetivo de promover a educação ambiental a partir de materiais utilizados durante o trajeto da trilha. Ao interpretar o ambiente, elas se apresentam como uma ferramenta pedagógica precisa para sensibilizar sobre a percepção da especialidade do meio natural, bem como propor um comportamento a ser adotado durante o trajeto, visando proteger o local e valorizá-lo.

As trilhas, além de interpretativas, também podem ser guiadas, quando se tem a presença de um guia na execução do trajeto, sendo que este deve apresentar conhecimento ao interpretar a trilha para os usuários. Os temas podem ser previamente estabelecidos, e também espontâneos, como nos casos de aparecimento de animais durante a caminhada, ou alguma espécie de planta. Nas trilhas autoguiadas não se tem a presença de um guia, os usuários seguem indicações de placas e outros recursos visuais que indicam o caminho a seguir. Estas indicações destacam árvores raras, espécies de plantas, entre outros (FONTES; VITORINO; SALVATI, 2006).

Para Lechner (2006), alguns potenciais podem estimular a implantação de trilhas, como aspectos cênicos e paisagens, recursos geológicos ou naturais singulares, oportunidades de interpretação da natureza e promoção da educação ambiental, dentre outros. Mas, além dos potenciais, existem algumas restrições como problemas de manejo, implantação de trilha em locais inadequados (devido ao solo), potencial acesso para caçadores e madeireiros ilegais, por exemplo.

De acordo com Andrade, Oliveira e Maganhotto (2011), além de ser uma opção de lazer na prática do turismo, as trilhas também podem ser utilizadas de forma educacional, na observação perante a especialidade do ambiente promovendo uma consciência ecológica. Porém estas devem ser cuidadosamente planejadas, proporcionando a valorização do ambiente natural e de uma utilização racional. O mau planejamento de um traçado traz sérios danos à fauna e flora do local, podendo trazer estragos irreversíveis ao meio ambiente. Portanto o planejamento adequado para a implantação de uma trilha é primordial para que haja os efeitos positivos, com o processo de implantação desta. 


\section{PLANEJAMENTO E IMPLANTAÇÃO DAS TRILHAS}

As áreas naturais devem ser cautelosamente planejadas e monitoradas ao se desenvolver algum tipo de atividade, tal como a abertura e readequação de trilhas. Deve haver a utilização coerente dos recursos naturais, proporcionando um equilíbrio quanto à ocupação do local pela atividade e à natureza, evitando impactos indesejados causados pelo uso deficiente do ambiente natural. Devem-se potencializar os benefícios gerados com a exploração racional do recurso, a fim de haver uma interação amigável do homem com a natureza (ANDRADE; OLIVEIRA; MAGANHOTTO, 2011).

Para realizar a abertura de trilhas e picadas, é necessário que se faça um planejamento e ordenamento adequado, para que não ocorram danos ao ambiente em que estão ou serão inseridas, pois estas representam uma relação estreita entre o homem e a natureza, o que pode descaracterizar o ambiente. Zimmerman (1951 apud FENNELL, 2002) aponta que "Os recursos não são, eles se tornam, não são estáticos, mas se expandem e se contraem em resposta às ações humanas". É, portanto, necessário compreender o local que será modificado para que os danos causados ao ambiente tornem-se minimizados.

As trilhas destinadas ao uso público em áreas naturais devem ser planejadas, implantadas e apresentar um manejo adequado, estando de acordo com o destino proposto para inseri-las. O planejamento deve atender às necessidades dos usuários, como a infraestrutura do trajeto, e resguardar os recursos presentes no ambiente. Primeiramente, deve ser pensado nos objetivos e na finalidade de implantá-la ou fazer o melhoramento de um traçado já existente; refletindo em quais serão as indicações durante o trajeto, as alterações a serem feitas minimizando os impactos negativos e potencializando os aspectos beneficentes (LECHNER, 2006).

Deve-se compreender o espaço a ser trabalhado, conhecer as condições do local na abertura de um traçado. De acordo com Lechner (2006) “[...] muitos impactos podem ser reduzidos ou eliminados, com o conhecimento dos processos naturais que atuam na área de implantação de trilhas [...]". Este processo oriunda do próprio ambiente, que tem a capacidade de se regenerar, mesmo sabendo que alguns dos impactos são inevitáveis, alguns deles podem ser reparados pela capacidade do local de se recuperar de tal impacto. 
Para o planejamento adequado de uma trilha, deve-se observar com cuidado o tipo de ambiente em que esta será inserida. Os tipos de paisagens a serem analisadas segundo Lechner (2006) são as paisagens resilientes, que têm a capacidade de se recuperar rapidamente dos impactos, as paisagens resistentes que se caracterizam por serem mais resistentes às atividades naturais, e as paisagens frágeis, que são aquelas facilmente impactadas e com capacidade de se recuperar vagarosa. Ao observar as características do ambiente, pode-se ter um controle sobre o impacto a ser gerado com a implantação de um trajeto.

Oliveira e Bloomfield (1999) explanam que, além do planejamento adequado, a manutenção de trilhas é outro item fundamental para prevenção e recuperação de danos causados ao ambiente e ao trajeto, como aparecimento de lama, erosão, sinalização danificada, locais escorregadios, surgimento de caminhos múltiplos gerados muitas vezes pela curiosidade dos visitantes em algo que está fora do trajeto. A manutenção aumenta a qualidade do traçado, auxiliando na recuperação e prevenção de danos e também facilita o seu uso.

Como afirma Lechner (2006), a vegetação é um dos itens a ser observado e que reflete diretamente nas condições do solo e da água, pois a vegetação necessita de condições específicas desses elementos, e, assimilando as necessidades das plantas, se podem conhecer as condições em que se encontra o ambiente da trilha. A interpretação da paisagem é uma etapa importante no planejamento, a fim de evitar que a intensificação do uso comprometa os aspectos da conservação ambiental.

As trilhas, segundo Andrade (2003, p. 247), "Terão papel significativo na impressão que o visitante levará sobre a área e a instituição que a gerencia". Portanto um traçado bem planejado, apresentando manutenção e utilização daquele ambiente de sua melhor forma é fundamental para a percepção que o usuário vai ter, sendo que o percurso pode ser um atrativo ou mesmo algo que cause uma má impressão sobre aquele local.

Lechner (2006) ainda aponta que a delimitação feita para marcar o traçado da trilha deve ser feita cautelosamente, pois, se for projetada acima da superfície, pode impedir o escoamento da água, causando acúmulo desta, formação de lama e erosão. A delimitação pode ser feita com pedras, 
troncos ou cordas, de modo que não impeça a drenagem natural da água. Quando há necessidade de demarcar um percurso, o meio de demarcar deve procurar a apresentar as mesmas características do local, buscando não contrastar com o ambiente natural.

De acordo com Lechner (2006) a sustentabilidade das trilhas é alcançada com o planejamento, construção e manutenção adequada. Considerando que, se o percurso for planejado e se houver manutenção adequada, são maximizados os efeitos benéficos para o ambiente e também para os usuários. O uso adequado do recurso é um meio de se reduzir os impactos gerados com a implantação e utilização da trilha.

\section{INFRAESTRUTURA PARA ABERTURA E MODIFICAÇÃO DE TRILHAS}

Ao implantar uma trilha ou infraestrutura, deve se analisar as oportunidades que o local oferece e as limitações do ambiente, como a composição da paisagem, a qual oferece informações importantes para seleção de locais que necessitam de drenagens, sinalização, corrimões, degraus, contenções, entre outras modificações. Qualquer tipo de infraestrutura causa impacto na paisagem, pois a modifica. Uma trilha bem implantada demonstra pouco da modificação vinda com a implantação desses instrumentos, mantendo o equilíbrio entre a natureza e as estruturas necessárias para melhorar o trajeto.

Com a abertura ou modificação de um traçado, o curso da água também muda. Pode ser necessário fazer drenagem, a qual pode ser feita, de acordo com Andrade (2003), por meio de canais laterais, para que a água escoe, ou canais na superfície da trilha. Outra medida é fazer uma barreira, para que a água acumulada desvie para as laterais da trilha. A escolha do tipo de estrutura a ser utilizada dependerá dos fatores físicos do traçado e dos usuários que utilizarão deste.

Para o escoamento da água, também se utiliza de bueiros para fazer a canalização em trechos que cortam olhos de água ou riachos. Estes podem ser construídos com pedras, plástico, aço ou com tubulação de cimento. O tamanho do bueiro vai depender da quantidade de água que será canalizada por ele; caso seja muito pequeno, tende a entupir. Mesmo tendo suporte adequado para escoamento da água, a manutenção é algo 
a ser feito regularmente, já que a permanência de folhas, galhos e outros resíduos tenderão a impedir o escoamento eficaz da água (LECHNER, 2006).

As obras de contenção, erosão e inserção de degraus, segundo Andrade (2003), devem ser implantadas junto com a drenagem. A inserção de degraus, em uma trilha, é considerada um dos elementos mais difíceis de ser implantado. Devem ser feitos somente se não houver outro meio, e os trechos que se utilizarão deste meio devem ser curtos. Os degraus podem ser de pedra ou de madeira (em pranchas ou em tronco). Para a contenção nas paredes da trilha, a fim de evitar a erosão, também podem ser utilizados pedras, madeira ou ambos.

As trilhas devem transmitir informações objetivas, e essas informações devem se apresentar em harmonia com a natureza. Portanto os materiais que farão parte da sinalização de uma trilha devem ser compatíveis com o meio natural, evitando, dessa forma, o impacto visual causado pela implantação desse tipo de infraestrutura (ANDRADE; OLIVEIRA; MAGANHOTTO, 2011).

Uma trilha sinalizada é fator relevante, para alertar sobre áreas de risco, proibições, educação ambiental, informações de acesso, atrativos, entre outros. Mas, para serem efetivas, as placas de sinalização devem não impactar com o ambiente natural, construídas com matéria prima natural durável, as quais podem ser tratadas com verniz, por exemplo. As informações devem ser objetivas e precisas, além de estarem presentes durante todo o trajeto, dando continuidade à mensagem que está sendo transmitida. A comunicação pode ser feita por mensagens escritas e também por meio de pictogramas (ANDRETTA et al., s/d).

Além das placas, existem outros métodos a serem adotados para fazer a sinalização, que podem ser, segundo Andrade (2003), por meio de panfletos; no caso das trilhas autoguiadas em que não se dispõe de placas, o folheto deve explicar adequadamente o caminho a ser seguido, fitas coloridas amarradas em troncos ou galhos de árvores, por meio de totens (monte de pedras) para marcar a direção a seguir; na utilização desse meio, indica-se marcar com tinta o topo do totem em locais sujeitos à neblina para ser mais bem visualizado. A sinalização com tinta deve manter um padrão de letras e modo de fixação e fazer o uso de cores que não contrastem com o meio ambiente. 
As lixeiras, outro componente da infraestrutura de uma trilha, devem se apresentar de forma a impedir que animais silvestres entrem dentro delas, já que estas podem ser uma forma fácil de obter alimento, o que pode influenciar na capacidade destes obterem seu alimento por sua própria natureza. Outro fator de risco é de estes animais ficarem presos dentro da lixeira e se afogarem após chuvas fortes ou morrerem por hipotermia. A presença de lixeiras evita que os usuários da trilha descartem resíduos de forma inadequada, visando assim valorizar a paisagem mantendo o local limpo e a boa impressão que o visitante levará do local, bem como proporcionar o cuidado com o meio ambiente (PONTES; MELLO, 2013).

Os pisos elevados, pontes e travessias de água são eficientes em trilhas que apresentem áreas baixas, úmidas ou que cortam cursos d'água, locais que, sem uma elevação, tornam a passagem mais difícil e também apresentam riscos aos caminhantes no cruzamento de rios e córregos. A estrutura de uma travessia ou ponte pode ser com uma tora colocada sobre o córrego, com cordas, estrutura de concreto, entre outros. A escolha da estrutura é feita de acordo com a necessidade da área e as características do local a ser implantado.

Depois da implantação de uma ponte, deve haver regularmente a monitoração desta, principalmente ao início de cada estação; o intervalo entre cada avaliação não deve ultrapassar seis meses e, mesmo nas estruturas mais simples, a inspeção é indispensável, o que vem a garantir a segurança dos usuários (LECHNER, 2006).

A infraestrutura de uma trilha é item fundamental para a qualidade do traçado e segurança dos usuários, já que dispõe de sinalização de indicação de riscos e de percurso a seguir, educação ambiental, atrativos durante o trajeto, equipamentos de apoio como degraus e corrimões, lixeiras, dentre outros itens. Porém a infraestrutura deve ser adequada com o ambiente em que está inserida, para que não cause impacto visual, e deve ter manutenção regular para que continue sendo um instrumento facilitador para os usuários e benéfico ao meio ambiente. 


\section{PROPOSTA DE REESTRUTURAÇÃO DO CIRCUITO DE TRILHAS DO PARQUE DA PEDREIRA EM RIO AZUL, PR}

O Parque Municipal Salto da Pedreira localizado no município de Rio Azul, região Centro Sul do estado do Paraná, foi criado em 1999 e tem uma área de $83.359 \mathrm{~m}^{2}$. Entre seus atrativos, estão a Cachoeira da Pedreira, com 15 metros de altura; o paredão de 30 metros, resultante da retirada de rochas para a construção da BR 153; uma piscina natural; e duas trilhas ecológicas que se estendem ao longo do curso do rio, que serão caracterizadas como A e B. O local ainda conta com mirante, quiosques, tanque para pesca esportiva, lanchonete e centro de eventos. A visitação no Parque bem como utilização da trilha é mais frequente nos fins de semana e ocorre de forma desordenada, devido à não existência de um controle e ou orientação dos visitantes.

Depois de feita observação de campo, percebeu-se que os trajetos necessitam de algumas benfeitorias, as melhorias sugeridas são para o aperfeiçoamento do traçado e tem importância para que haja valorização do local, maior segurança para os usuários e manutenção do ambiente.

Na trilha A, o percurso é linear, portanto a ida e a volta são feitas pelo mesmo trajeto, envolvendo uma caminhada fácil. A extensão do percurso é de 418 metros, a vegetação apresenta árvores e plantas nativas e nota-se uma presença marcante de bambus, barulho da correnteza do rio e a presença de pássaros durante o percurso. A trilha se estende pela margem do rio, que pode ser acessado em alguns pontos do traçado.

O primeiro ponto em que se sugere melhoria é na cabeceira da trilha. $O$ percurso se inicia sem sinalização, porém o traçado é facilmente visualizado, neste ponto se encontra a única lixeira inserida próximo à trilha. Também se pode ver uma placa de segurança e uma cerca que impede o caminhante de sair do traçado, porém está apenas em partes do trajeto, não acompanha o percurso inteiro. Nesse local, se pode fazer a indicação do início da trilha A, através de um painel contendo informações da extensão do percurso, grau de dificuldade e informações educativas voltadas ao cuidado ambiental. Sugere-se fazer essa sinalização no local indicado na Imagem 1. 
Imagem 1- Cabeceira da trilha A

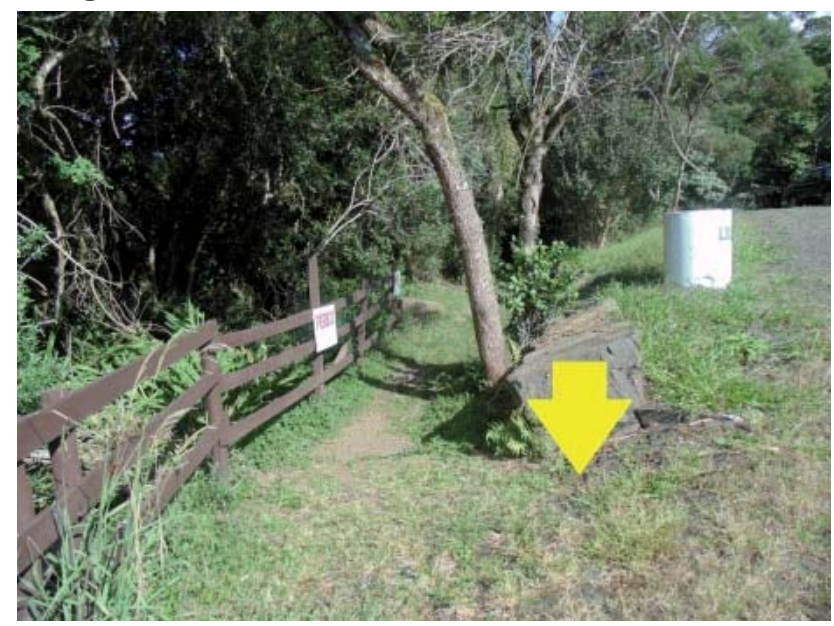

Fonte: Acervo pessoal (2017)

O segundo ponto sugerido é um acesso ao rio, durante o trajeto existem 3 acessos que permitem chegar até o rio. 0 primeiro acesso ao rio, o que se sugere melhoria, permite chegar em cima da queda da cachoeira. Nesse ponto, recomenda-se a colocação de um banco, impedindo que os usuários passem; junto com o banco, também inserir uma placa de advertência. O local pode ser observado na imagem 2.

Imagem 2- Acesso 1 ao rio

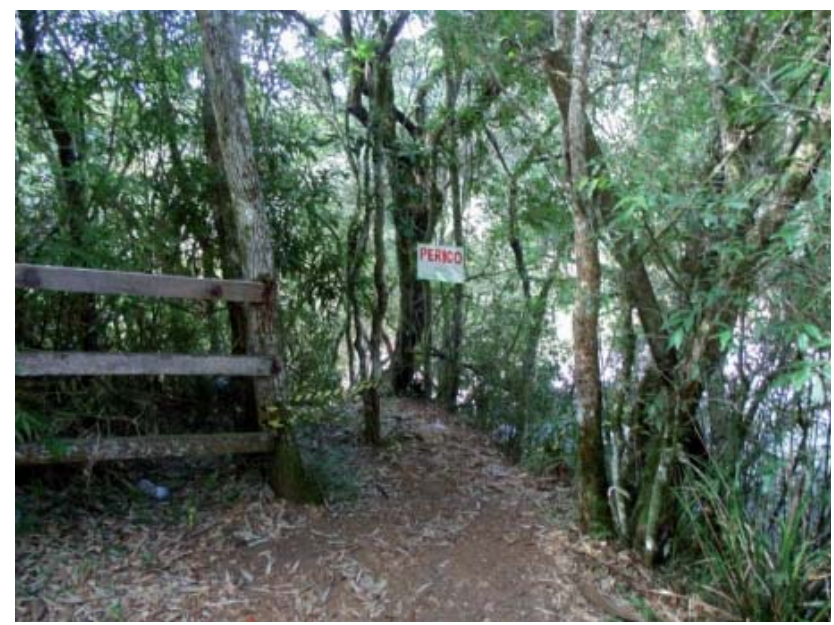

Fonte: Acervo pessoal (2017) 
No segundo acesso para o rio, também se sugere uma modificação, o acesso é feito por uma trilha estreita e íngreme. Apresenta pedras e algumas árvores que favorecem a subida e descida até o local, estes são os únicos auxílios utilizados para atingir essa área, considerando que o trajeto se torna escorregadio em dias de chuva. Nessa parte do percurso, sugere-se fazer um mirante ao final do acesso ao rio, pois o local oferece uma visão ampla do rio Cachoeira. Esse ponto pode ser observado na imagem 3.

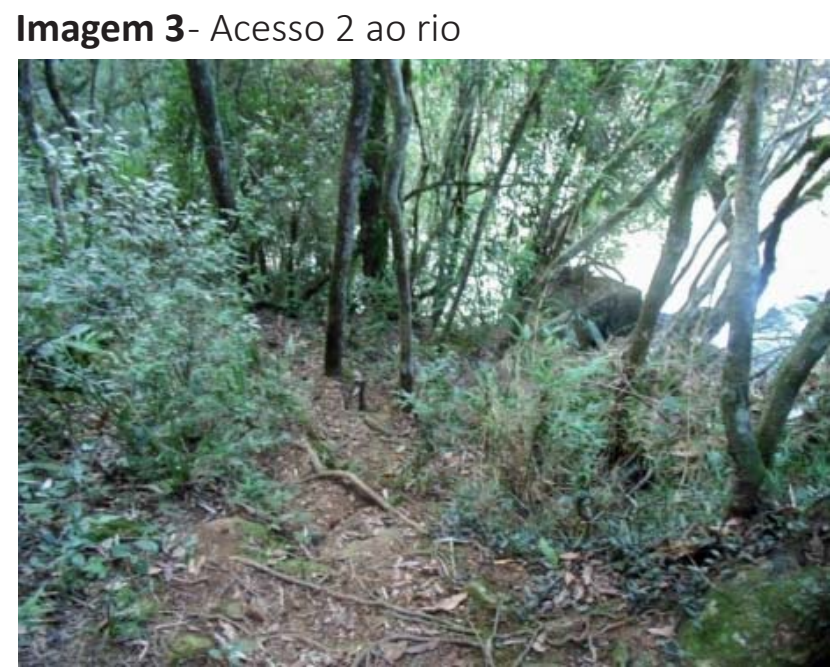

Fonte: Acervo pessoal (2017)

A última proposta de melhoria para a trilha $\mathrm{A}$, é a realocação de uma parte do traçado da trilha. Sugere-se uma mudança no traçado nesse ponto da trilha, realocando para um pouco acima da margem direita, próximo ao indicado na Imagem 4, para que a vegetação e o solo se recuperem, já que, além do escoamento, nesse ponto apresenta raízes expostas e solo compactado, o que são impactos percebidos na trilha. A margem do traçado está próxima de um barranco, tornando-a uma área de risco, outro fator relevante para fazer a modificação.

Nessa parte do trajeto, que é aproximadamente metade de todo percurso, pode-se inserir uma área para descanso como uma mesa, bancos, placa educativa e uma lixeira junto do local da realocação da trilha, considerando que esses itens cumprem o objetivo que prioriza a localização de 
pontos que necessitam infraestrutura. A sugestão de mudança pode ser observada na imagem 4.

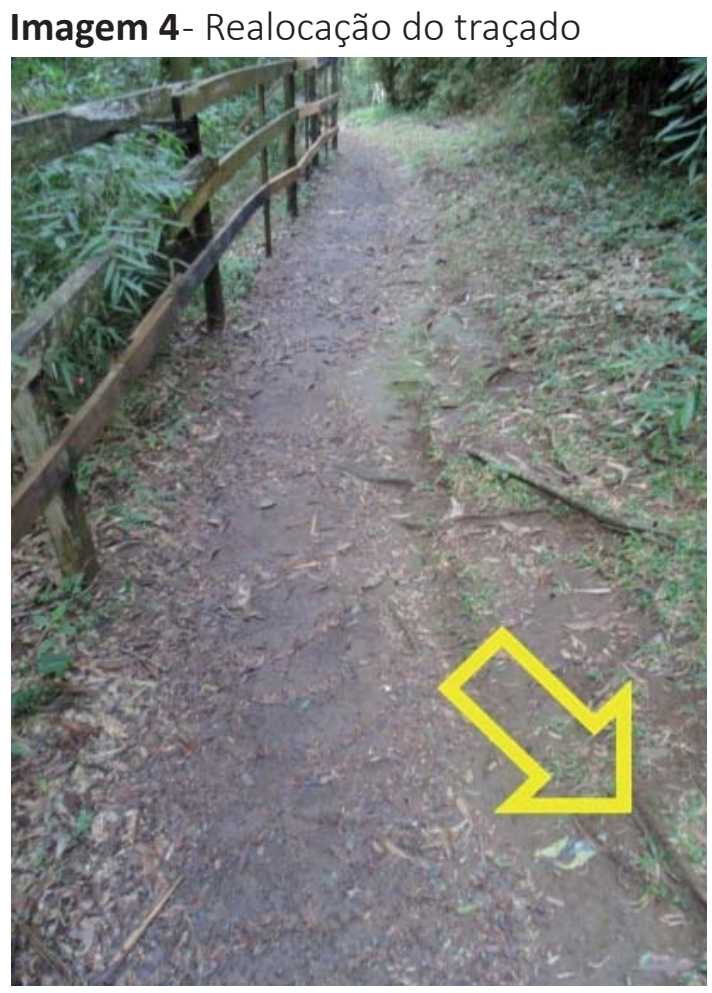

Fonte: Acervo pessoal (2017)

O terceiro acesso ao rio, localizado próximo ao fim da trilha, apresenta declividade alta oferecendo riscos aos usuários e o desencadeamento de processos erosivos. Por isso, pensando na questão ambiental que envolve a inserção de algum tipo de estrutura para facilitar o acesso e oferecer maior segurança aos usuários, sugere-se o bloqueio desse ponto, por meio de um atalho na trilha pelo lado direito, com o trajeto seguindo pouco acima de onde já está implantado; o local em que se sugere o desvio é destacado na Imagem 5. Para fazer o bloqueio, pode-se colocar um banco para descanso, junto de uma placa educativa, e uma lixeira, visando à sensibilização ambiental. 


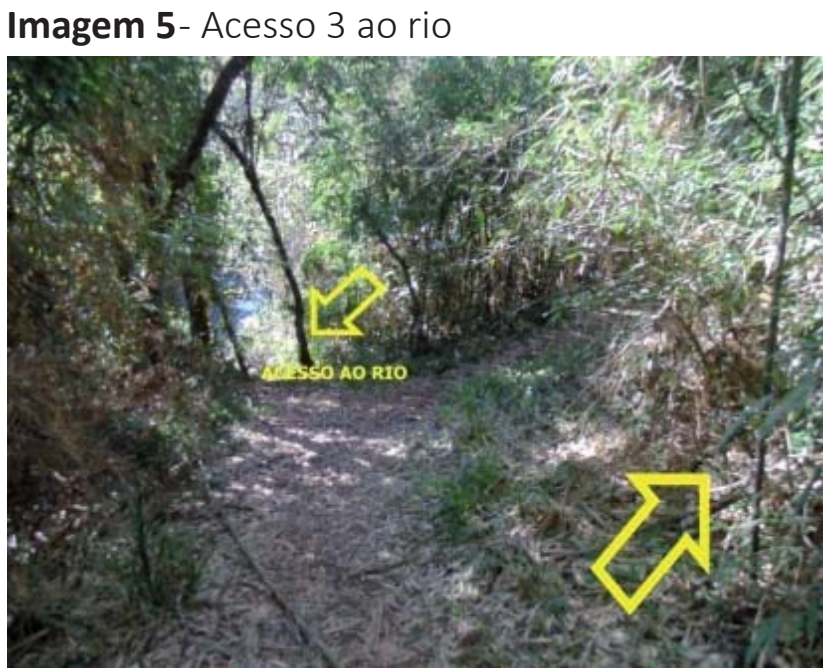

Fonte: Acervo pessoal (2017)

Outro ponto em que foi percebida a necessidade de benfeitorias é na implantação da sinalização, em diversos pontos foram observadas irregularidades. A sinalização implantada de forma inadequada traz impactos negativos sobre o meio, como se pode ver na imagem 6 , a placa indicando área de risco está fixada em uma árvore e se encontra parcialmente coberta pela vegetação. Nos pontos em que há necessidade desse tipo de aviso, é possível fixar as placas no chão em paralelo com o traçado da trilha. Considerando que a sinalização tem por objetivo a segurança dos caminhantes e dos recursos do local, de acordo com Andrade (2003), esta deve ser implantada de forma a não descaracterizar o ambiente e apresentar mensagens claras e objetivas quanto à mensagem a ser passada. A fixação das placas pode ser em postes de madeira ou com montes de pedras, e também pode ser fixada em árvores com cordas de nylon. O tipo de inserção das placas é escolhido de acordo com as características de cada local. Para as de madeira devem ser considerados alguns item como a durabilidade e impermeabilidade, também analisar a dimensão adequada para fácil visualização das mensagens que podem ser educativas, informativas, de advertência entre outras. 


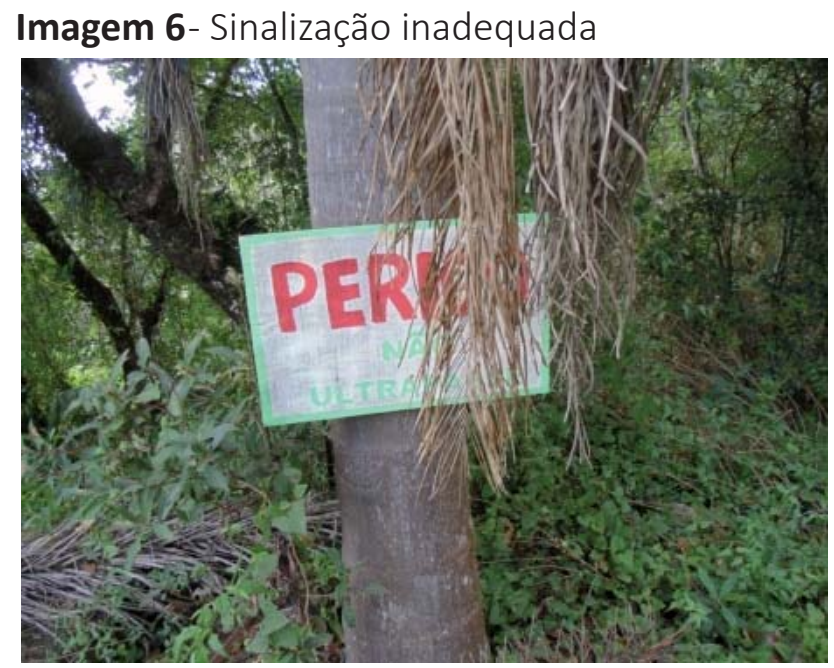

Fonte: Acervo pessoal (2017)

Na trilha B, o percurso é também, linear, sendo ida e volta por uma escadaria com degraus de pedras irregulares. O trajeto envolve uma caminhada leve com distância de 70,5 metros que permite chegar até a base da cachoeira. A vegetação apresenta árvores e plantas nativas, e se torna mais densa do outro lado da margem do rio.

A primeira sugestão de melhoria também se inicia na cabeceira do trajeto, pois o acesso até a cachoeira inicia sem sinalização. A flecha inserida na Imagem 7 é o local sugerido para que seja colocada uma placa indicativa do acesso da trilha $B$. 
Imagem 7- Cabeceira da trilha B

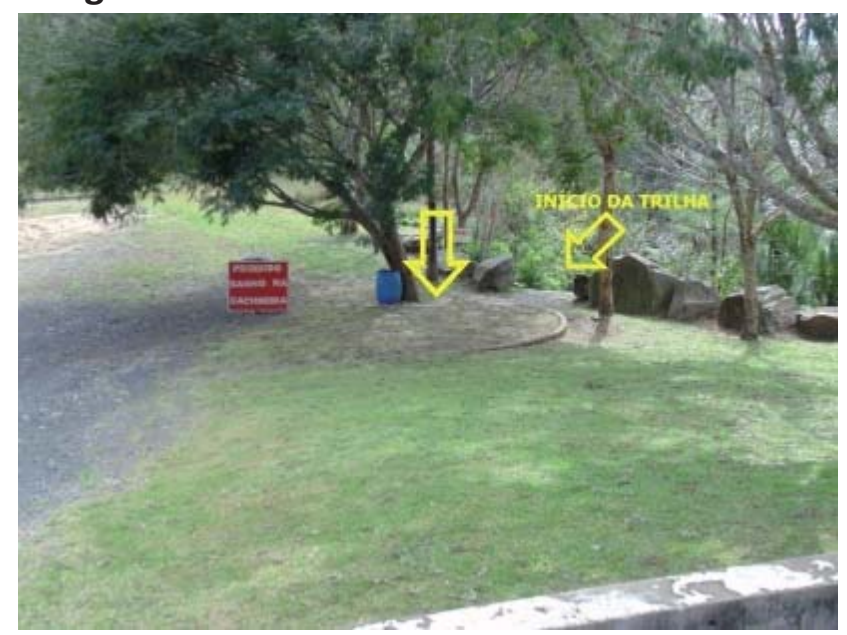

Fonte: Acervo pessoal (2017)

Em alguns pontos da escadaria de acesso à cachoeira, foi verificada a falta de blocos de pedra que compõem os degraus, causada pela falta de manutenção da trilha como pode ser observado na imagem 8. Sugere-se recolocar as pedras que se soltaram da escadaria, fornecendo mais segurança, conforto aos caminhantes e melhorando a estética do local, o que reforça a necessidade de manutenção.

Imagem 8- Manutenção da escadaria

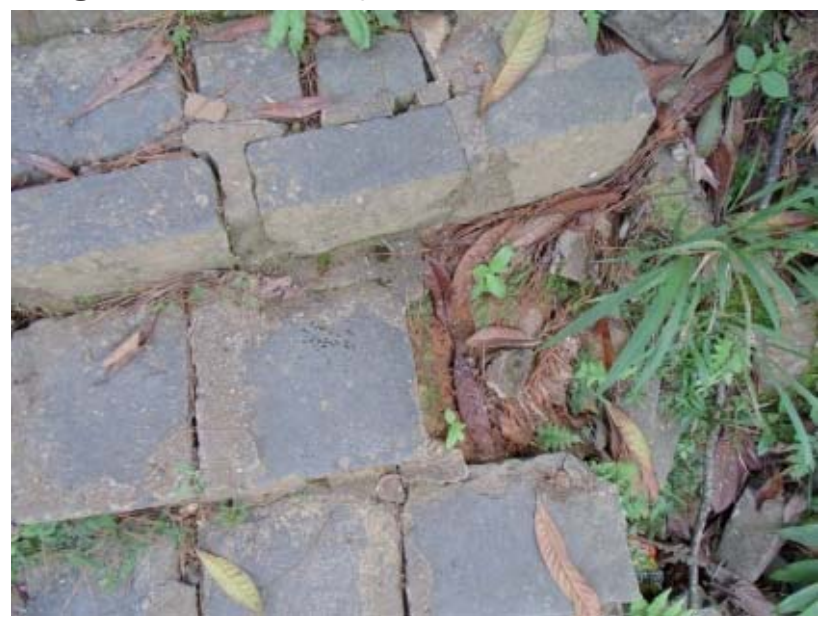

Fonte: Acervo pessoal (2017) 
Na imagem 9, pode-se ver que o bueiro de escoamento não é suficiente para canalizar toda a água, que acaba invadindo o trajeto e oferecendo risco para os caminhantes, pois o acesso se torna escorregadio. Para esse problema, é necessário fazer um canal de escoamento com saída maior, para que a água não passe por cima da calçada, sendo este outro ponto do trajeto que necessita de manutenção na infraestrutura.

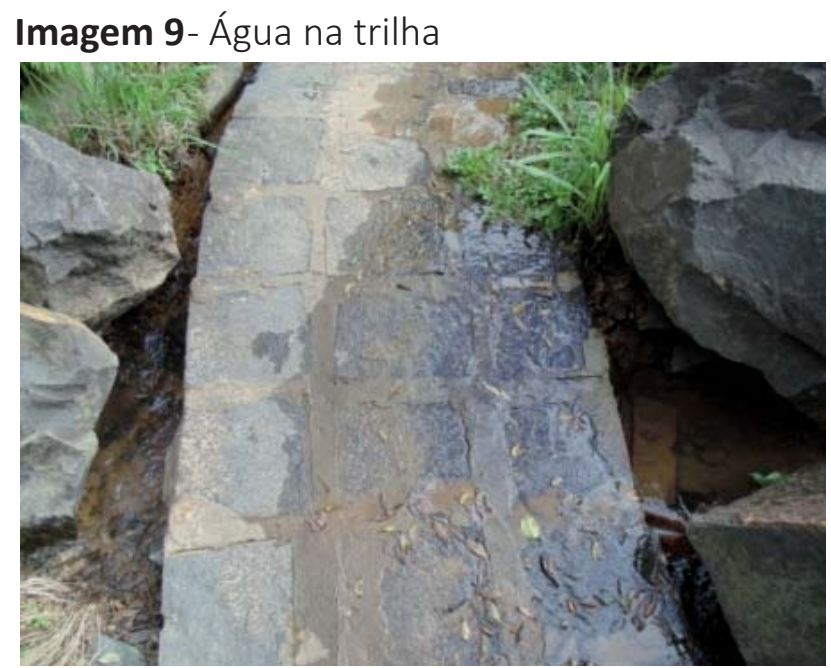

Fonte: Acervo pessoal (2017)

Um impacto observado na trilha da escadaria é a erosão causada por uma forte chuva, o que resultou no deslocamento de pedras devido à elevação do nível do rio e força da correnteza, observando que uma dessas pedras está no meio da calçada de acesso. Sugere-se fazer uma contenção na área danificada pela erosão e realocação das pedras que se encontram na margem da trilha, como pode ser visto na Imagem 10, para facilitar o deslocamento dos usuários, sendo que essas pedras deslocadas podem ser usadas para fazer contençao em outros pontos do trajeto. 
Imagem 10- Erosão

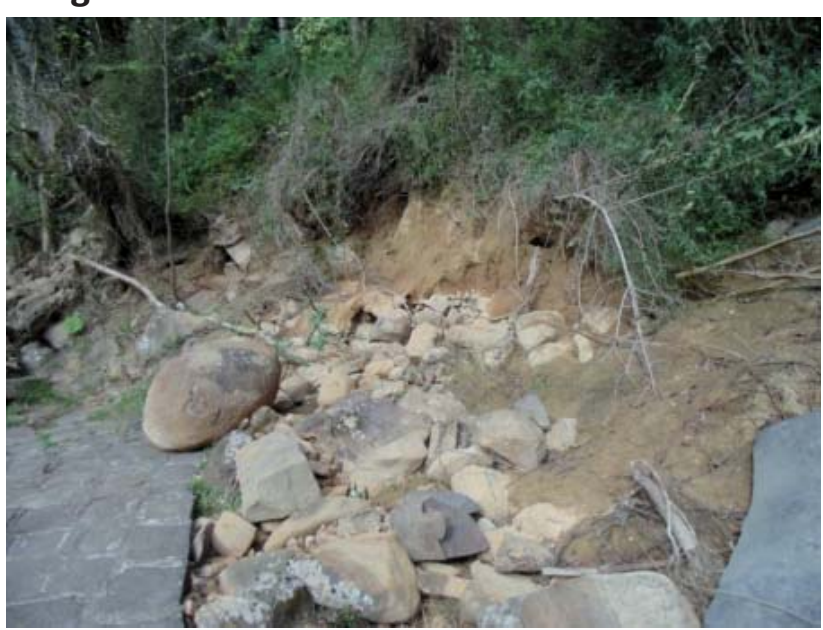

Fonte: Acervo pessoal (2017)

\section{CONSIDERAÇÕES}

Com a pesquisa bibliográfica, obteve-se maior conhecimento sobre a temática que abrange o estudo, sendo item fundamental para reconhecimento e análise das áreas afetadas e que necessitam de maior atenção no estudo de campo. A pesquisa foi relevante para obter maior aprofundamento sobre os elementos que envolvem áreas naturais, os segmentos do turismo que podem ser praticados nesses ambientes, trilhas e seu uso pelo turismo.

A partir dos resultados obtidos com as pesquisas teóricas e as visitas a campo, observou-se que o circuito de trilhas do Parque Municipal Salto da Pedreira necessita de benfeitorias em alguns pontos do traçado, estas que priorizam cumprir os objetivos propostos pelo trabalho.

Foram sugeridas melhorias nas trilhas $A$ e $B$, as quais estão relacionadas ao cumprimento de três objetivos específicos propostos, sendo o primeiro deles identificar os impactos presentes na trilha existente. Estes foram identificados nas duas trilhas, como compactação do solo, acúmulo de água no trajeto, raízes expostas, infraestrutura e sinalizações inadequadas e erosão.

O segundo objetivo alcançado foi com a localização dos pontos do traçado que necessitam de infraestrutura e sugestão de ações relacionadas 
ao cumprimento deste. No trajeto das duas trilhas, foram identificados locais que necessitam de implantação e readequação desta, como a limpeza de melhoramento de bueiros, implantação de mirante, bancos para descanso e lixeiras.

O terceiro objetivo, sugerir locais para implantação de informações relacionadas às trilhas; para o cumprimento deste, foram sugeridos alguns locais que não apresentavam sinalização de acesso, nas duas trilhas, painéis com instruções sobre a trilha, e placas educativas.

Estas são algumas das melhorias que podem deixar o Parque da Pedreira com atrativos de qualidade, segurança e bem-estar para os visitantes. Frisa-se que se trata de um ambiente natural, em que o cuidado e a preservação devem ser fator primordial para o sucesso da atividade turística que já é efetiva no local.

\section{REFERÊNCIAS}

ANDRADE, Aparecido R.; OLIVEIRA, Oseias; MAGANHOTTO, Ronaldo F. Turismo e sustentabilidade em comunidade quilombola. Guarapuava, PR: Ed. Unicentro, 2011. ANDRADE, Waldir J. Implantação e manejo de trilhas. In: MITRAUD, Sylvia (Org.). Manual de Ecoturismo de Base Comunitária: ferramentas para um planejamento responsável. Brasília: WWF Brasil, 2003. 470p.

ANDRETTA, Vanessa et al. Sinalização de trilhas: importância e eficiência. [s/d]. Disponível em: <http://pt.scribd.com/doc/11566793/SINALIZACAO-DE-TRILHASIMPORTANCIA-E-EFICIENCIA>. Acesso em: 21 nov. 2017.

DIAS, Reinaldo. Turismo sustentável e meio ambiente. São Paulo: Atlas, 2003.

FENNELL, David. Ecoturismo uma introdução. São Paulo: Pinsky, 2002.

FONTES, Marco A. L.; VITORINO, Maria R.; SALVATI, Sérgio S. Trilhas: qual a importância destes caminhos para o ecoturismo? 2006 . Disponível em: <http:// ambientes.ambientebrasil.com.br/ecoturismo/artigos/trilhas_-_ecoturismo.html>. Acesso em 20 mai. 2014.

INSTITUTO BRASILEIRO DE TURISMO (EMBRATUR). Manual de ecoturismo. Brasília, maio 1994.

KINKER, Sônia. Ecoturismo e conservação da natureza em parques ambientais. Campinas, SP: Papirus, 2002.

LAVOURA, Tiago N.; SCHWARTZ, Gisele M.; MACHADO, Afonso A. Aspectos emocionais da prática de atividades de aventura na natureza: a (re) educação 
dos sentidos. Revista Brasileira de Educação Física, São Paulo, v. 22, n. 2, p. 11927, abr./jun. 2008. Disponível em: <http://www.revistas.usp.br/rbefe/article/ viewFile/16687/18400>. Acesso em 18 nov. 2017.

LECHNER, Larry. Planejamento, implantação e manejo de trilhas em unidades de conservação. Cadernos de Conservação, Fundação O Boticário de Proteção à Natureza, ano 3, n. 3, jun. 2006.

LICKORISH, Leonard J.; JENKINS, Carson L. Introdução ao turismo. Rio de Janeiro: Campus, 2000.

OLIVEIRA, Antônio P. Turismo e desenvolvimento: planejamento e organização. São Paulo: Atlas, 2002.

OLIVEIRA, Renata T. de; BLOMMFIELD, Vanessa K. Trilha auto guiada: proposta de implantação e interpretação na Floresta Nacional Mário Xavier Sandra Regina da Costa. Revista Floresta e Ambiente, Rio de Janeiro, v. 6, n. 1, p. 138-43, 1999. Disponível em: <http://www.geocities.ws/floramrural/p0138.pdf>. Acesso em: 26 nov. 2017.

PAPINI, Luis F. de M.; COSTA, Nadja M. C. da; COSTA, Vivian C. Avaliação do grau de dificuldade em trilhas ecoturísticas no ParqueEstadual da Pedra Branca. 2006. Disponível em: <https://pt.scribd.com/doc/11566662/Avaliacao-do-grau-dedificuldade-em-trilhas-ecoturisticas-no-Parque-Estadual-da-Pedra-Branca-RJ>. Acesso em 30 nov. 2017.

PONTES, Jorge A. L.; MELLO, Flávio A. P. Uso público em unidades de conservação de proteção integral: considerações sobre impactos na biodiversidade. Uso público em unidades de conservação, Rio de Janeiro, v. 1, n. 1, 2013. Disponível em: <http:// www.uff.br/var/www/htdocs/usopublico/images/Artigos/2013/Artigo_OL_22.pdf>. Acesso em: 28 nov. 2017.

RUSCHMANN, Dóris. Turismo e planejamento sustentável - a proteção do meio ambiente. Campinas, SP: Papirus, 1997. 